\title{
Cicatrización de injertos cutáneos en malla de espesor completo utilizando azúcar granulado versus nitrofurazona en caninos
}

\author{
Pintos, S.'; González, R. ${ }^{1}$; González, E. ${ }^{2}$ \\ ${ }^{1}$ Departamento de Patología y Clínica, ${ }^{2}$ Dirección Académica, Facultad de Ciencias Veterinarias, \\ Universidad Nacional de Asunción, San Lorenzo, Paraguay. E-mail: spintos@vet.una.py
}

\begin{abstract}
Resumen
Pintos, S.; González, R.; González, E.: Cicatrización de injertos cutáneos en malla de espesor completo utilizando azúcar granulado versus nitrofurazona en caninos. Rev. vet. 26 : 2, 103-107, 2015. El objetivo del trabajo fue evaluar el proceso de cicatrización del injerto de malla de espesor completo en caninos, utilizando dos tratamientos tópicos: azúcar granulado y nitrofurazona. Fueron utilizados cuatro animales de la misma camada, manipulados en iguales condiciones ambientales, nutricionales y de manejo sanitario. Los sujetos experimentales se dividieron en dos grupos, uno de ellos fue tratado con nitrofurazona al 0,2\% y el otro con azúcar granulado. Los resultados fueron evaluados en función al tiempo de cicatrización, tiempo del relleno de la cavidad de la malla y tiempo de retiro del vendaje. El tiempo total de cicatrización del injerto fue menor en los perros tratados con azúcar granulado (42 días) en comparación a los medicados con nitrofurazona (54 días), aunque las diferencias no fueron significativas. En cambio, fueron encontradas diferencias estadísticamente significativas $(p<0,05)$ para las variables tiempo de relleno total de la cavidad de la malla y tiempo de retiro del vendaje, que resultaron menores en los animales tratados con azúcar. La histopatología reveló que estos últimos desarrollaron adecuados procesos de cicatrización, caracterizados por la uniformidad del estrato epidérmico y el paralelismo de las fibras colágenas. En cambio, los tratados con nitrofurazona exhibieron patrones no uniformes e infiltrados de células inflamatorias.
\end{abstract}

Palabras clave: perro, injerto en malla, azúcar, nitrofurazona.

\begin{abstract}
Pintos, S.; González, R.; González, E.: Healing of skin graft in complete thickness mesh using granulated sugar versus nitrofurazone in dogs. Rev. vet. 26: 2, 103-107, 2015. The aim of this study was to evaluate the healing process of full-thickness mesh skin graft using two topical treatments: granulated sugar vs. nitrofurazone. For this purpose, four animals of the same litter were manipulated with equal sanitary handling and similar environmental and nutritional conditions. The experimental animals were divided in two groups: first group was treated with $0.2 \%$ nitrofurazone, second group with granulated sugar. Results were measured in function of healing time (in days) considering variables such as total healing time, mesh cavity filling time, and time of removal. Healing time of skin graft was shorter in the dogs treated with granulated sugar (42 days) compared to those treated with nitrofurazone (54 days), although the differences were not significant. On the other hand, significant differences $(p<0.05)$ were found for the time of mesh cavity filling and time of bandage removal, being both variables shorter for the animals treated with sugar. Histopathological studies revealed that the latter developed appropriate scaring processes characterized by the uniformity of the epidermal stratum and parallelism of the collagen fibers. On the other hand, animals treated with nitrofurazone exhibited abnormal patterns and presence of inflammatory cells.
\end{abstract}

Key words: dog, sking graf, sugar, nitrofurazone.

\section{INTRODUCCIÓN}

Un injerto cutáneo es un segmento de epidermis y dermis que es completamente removido del cuerpo y

Recibido: 23 abril 2015 / Aceptado: 16 junio 2015 transferido a un sitio receptor. Su sobrevida en el sitio depende de la absorción del líquido tisular y del desarrollo de un nuevo aporte de sangre.

Desde el punto de vista clínico, los autoinjertos son el tipo más exitoso y se los utiliza en forma permanente porque injerto y huésped son antigénicamente idénti- 
cos. Los xenoinjertos y los aloinjertos pueden emplearse como cobertura temporaria de grandes áreas quemadas o denudadas; sin embargo, son eventualmente rechazados. Los injertos pueden ser de espesor completo (compuestos por epidermis y toda la dermis) o parcial (compuestos por la epidermis y un espesor variable de la dermis) ${ }^{12}$.

La epitelialización que sucede a la implantación del injerto, ocurre con mayor rapidez en un ambiente húmedo que en otro seco. No se producirá sobre tejido sin viabilidad. La contracción de la herida reduce el tamaño lesional posterior a la contracción de los microfibroblastos en el tejido de granulación; se produce en forma simultánea con la granulación y epitelialización pero es independiente de esta última. Los bordes cutáneos de espesor completo, centrípetos, son traccionados hacia adentro mediante la contracción y las heridas pueden ser llamativamente más pequeñas hacia los 5-9 días después de la lesión ${ }^{4,6}$.

Aunque las técnicas para injerto de piel en las personas son aplicables a perros y gatos, en veterinaria difieren el vendaje y los cuidados post-quirúrgicos. La sujeción del paciente, el mantenimiento de un vendaje efectivo y la prevención de la contaminación son los principales problemas en el injerto canino ${ }^{11}$. Las tres causas más comunes de falla del injerto son su separación del lecho receptor, la infección y el movimiento ${ }^{12}$.

El azúcar (sacarosa) obtenido de la caña de azúcar $^{12}$. Su forma granulada ("azúcar de mesa") y la miel han sido utilizadas desde antes de la era cristiana para la cicatrización de heridas en seres humanos. Actualmente son empleadas en todo el mundo para tratar heridas contaminadas y lentamente están empezando a tener aceptación en medicina veterinaria. A pesar de los excelentes resultados obtenidos, el mecanismo de acción de estas sustancias recién fue dilucidado en el siglo $\mathrm{XX}^{2,3,5,13}$.

Entre las particularidades del azúcar figura la ventaja de no tener fecha de caducidad y, por su proceso de elaboración, sale de fábrica totalmente estéril. La sacarosa posee propiedades antibacterianas, bacteriostáticas, antisépticas, desbridantes, antiedematosas, inmunológicas, estimulantes de la cicatrización y no se absorbe por vía tópica ni provoca irritación. Su aplicación en piel y mucosas genera una presión osmótica que deshidrata el citoplasma bacteriano, provocando por un lado la lisis bacteriana y por otro la incapacidad reproductora de las bacterias no lisadas de las heridas ${ }^{2,16}$.

El azúcar crea un medio con bajo contenido de agua (alta osmolaridad), que genera migración de agua y linfa fuera del tejido, hacia la solución de azúcar, inhibiendo el crecimiento bacteriano por disminución de la "actividad de agua" (Aw) del sustrato, mientras la linfa continúa suministrando nutrientes al tejido. La "Aw" es la relación entre la presión de vapor del agua de un sustrato en relación con la presión del vapor de agua pura a la misma temperatura. En otras palabras, es la medida del agua disponible que existe en un sustrato y depende del tipo y cantidad de interacciones del agua con otros componentes de dicho sustrato. La Aw influye en el crecimiento, la resistencia y la supervivencia de los microorganismos ${ }^{15}$.

Además, el azúcar atrae macrófagos, que participan en la "limpieza de la herida", acelerando el desprendimiento de tejido desvitalizado, necrótico y/o gangrenoso, aportando una fuente de energía local y formando una capa proteica protectora en la herida. El azúcar no solo absorbe líquidos del citoplasma de las bacterias, sino de las células superficiales del lecho de la herida.

Tales células superficiales, al contrario de las bacterias, están conectadas unas con otras, por lo que no se produce deshidratación de las mismas, sino una migración de líquidos y sangre de los sustratos profundos a la superficie de la herida, llegándose a formar microcapilares, conformando una herida más nutrida y húmeda, que ayuda al desbridaje y evita los malos olores al acabar con los esfacelos y el sustrato bacteriano, generando una cicatrización más fisiológica, rápida, limpia, barata y consolidada. La concentración de macrófagos acumulados en la lesión, conlleva a un aumento de los fibroblastos e incentiva la producción de colágeno, por lo cual al cabo de una semana aparecerá el tejido de granulación $^{2-4}$.

El azúcar posee asimismo propiedades desodorizantes ya que las bacterias usan glucosa en lugar de aminoácidos para su metabolismo, produciendo ácido láctico en lugar de sustancias malolientes (amonio, aminas y compuestos azufrados) ${ }^{3}$. La presencia cada vez más numerosa de mascotas en la actividad familiar cotidiana hace que éstas se vean más expuestas a traumatismos físicos o químicos, que muchas veces, además de causar trastornos de origen sistémico, generan pérdidas importantes tejido cutáneo. Al momento de la sutura, tal ausencia de tejido cutáneo obliga a la aproximación de la piel bajo tensión, lo cual redunda en dolor y alteraciones de la cicatrización, con probable dehiscencia de las suturas realizadas. El azúcar ayudará a evitar estos trastornos. Permitir la persistencia del dolor no solo es incorrecto desde la perspectiva ética, sino que tiene consecuencias biológicas perjudiciales. El dolor persistente es un estresante mayor que afecta desde la cicatrización de las heridas hasta la resistencia a las infecciones ${ }^{7,8}$.

El propósito de este trabajo fue verificar la optimización del proceso de cicatrización utilizando azúcar granulado en injertos cutáneos en malla de espesor completo con la expectativa que el injerto cubriera la superficie de la herida y el azúcar proveyera los factores necesarios para un correcto proceso de cicatrización, constituyendo ambos un sinergismo orientado a una curación más rápida y sin complicaciones. En los perros, el injerto cutáneo está principalmente indicado para los traumas tegumentarios de las extremidades, donde la inmovilidad de la piel evita el estiramiento y la construcción de colgajos locales para reparar defectos. Los injertos cutáneos son utilizados en ocasiones, para dar cobertura a quemaduras de espesor completo después de un daño térmico importante. 
El objetivo propuesto fue evaluar clínica e histopatológicamente el proceso de cicatrización del injerto cutáneo en malla de espesor completo, comparando las ventajes de la utilización del azúcar de mesa versus un antibiótico bactericida (nitrofurazona) como agentes terapéuticos en el proceso de cicatrización, con especial énfasis a la descripción del grado de reacción tisular.

\section{MATERIAL Y MÉTODOS}

La investigación fue llevada a cabo en el Hospital "Prof. Dr. José Vicente Núñez Núñez" de la Facultad de Ciencias Veterinarias de la Universidad Nacional de Asunción (Paraguay). Fueron utilizados cuatro perros pertenecientes a una misma camada y en buen estado de salud y nutrición, los cuales se agruparon en dos grupos, según el tratamiento. Un grupo $(n=2)$ fue sometido a cirugía y aplicación de antibiótico tópico (nitrofurazona al $0,2 \%$ ), en tanto que el otro $(n=2)$ fue operado y tratado con aplicaciones tópicas de azúcar granulado.

Los animales seleccionados fueron confinados en un canil y mantenidos con la madre hasta los 45 días de vida. La alimentación consistió básicamente en leche materna y a partir del día 30 de vida se proporcionó de manera gradual alimentación balanceada comercial para cachorros. Posteriormente, los animales siguieron confinados en caniles individuales hasta los 32 meses de vida (adultez), momento en que se inició el estudio.

El área quirúrgica utilizada correspondió a la piel de la región costal a nivel del tercio medio del tórax del lado izquierdo. El tamaño de la incisión fue de $7 \mathrm{~cm}$ de largo x $7 \mathrm{~cm}$ de ancho, aproximadamente. La incisión fue previamente demarcada con un marcador especial indeleble de uso en cirugía. A continuación se procedió a realizar la incisión de la piel y disección del tejido conjuntivo subcutáneo (Figuras 1 y 2). El segmento de piel terminó siendo extirpado y la herida fue cubierta con un paño embebido con solución fisiológica templada estéril.

A continuación fue realizada la malla según el siguiente procedimiento: el segmento cutáneo fue colocado con el lado dérmico hacia arriba en una bandeja de acero inoxidable estéril con suero fisiológico y seguidamente fue traccionada suavemente hacia los lados con pinzas de campo de Backhaus para así realizar incisiones de la piel, en sentido longitudinal, de aproximadamente 0,5 a $1 \mathrm{~cm}$ y a intervalos de 0,2 a $2 \mathrm{~cm}$ a efectos de confeccionar la malla y constituir un verdadero injerto en malla de espesor completo, asegurando de que la malla se abriera a modo de permitir el drenaje. De cada uno de los bordes del tejido fueron extirpados segmentos longitudinales de $2 \mathrm{~mm}$ de ancho (Figura 3).

Una vez preparado, el injerto fue colocado inmediatamente sobre la herida provocada por la misma extirpación de piel, ya que ésta fue reciente y se consideró que la vascularización fue correcta como para producir un adecuado tejido de granulación. Fueron fijados puntos interrumpidos simples de nylon 3-0 para fijar un

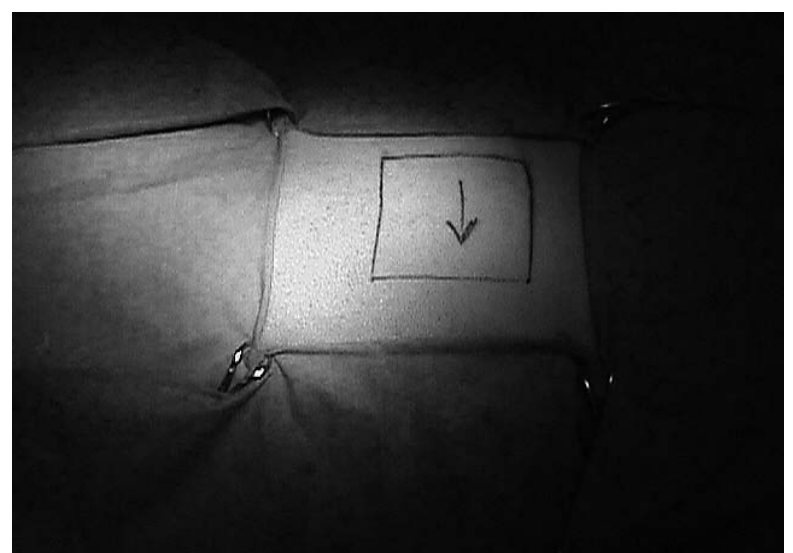

Figura 1. Preparación del campo operatorio en la zona costal, previendo incisiones de $7 \times 7 \mathrm{~cm}$.

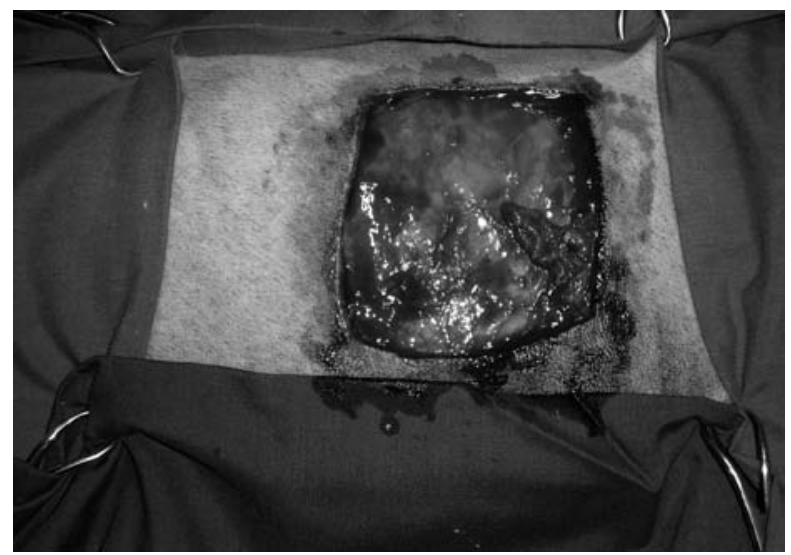

Figura 2. Solución de continuidad luego de la extirpación del segmento cutáneo.

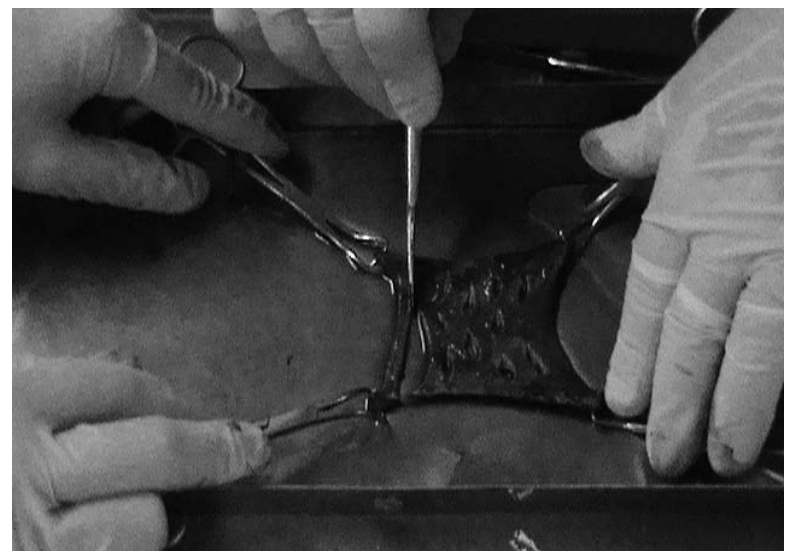

Figura 3. Realización de incisiones que constituyeron la malla del futuro injerto.

borde del injerto a la piel a lo largo de los bordes de la herida. Primero fueron colocados en los 4 ángulos y luego en los demás puntos a lo largo de cada uno de los bordes (Figura 4).

A dos perros se les colocó un vendaje con estrato de contacto no adherente y estéril junto con una delgada cobertura de ungüento antibiótico a base de nitrofurazona al $0,2 \%$, en tanto que a los otros dos se les aplicó azúcar granulado (Figuras 5 y 6).

El estrato de contacto se cubrió con una venda elástica como estrato secundario y éste con material espa- 


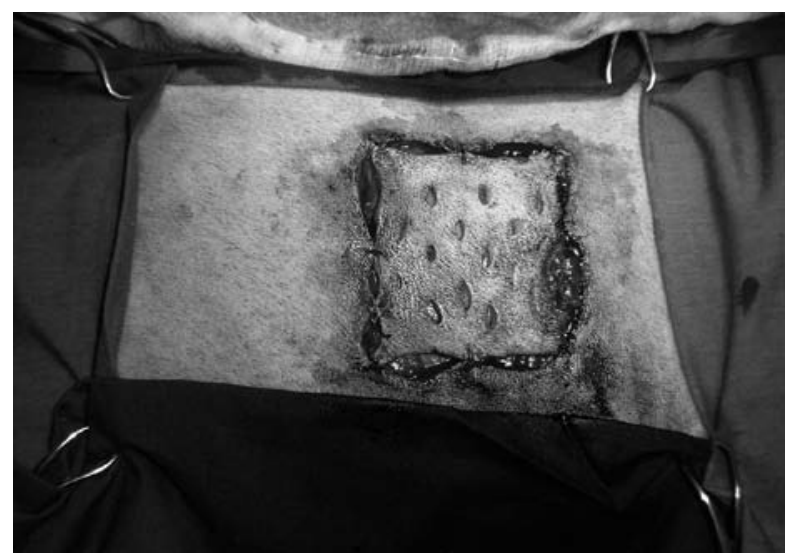

Figura 4. Puntos de sutura ubicados a distancias equidistantes a lo largo de la línea de sutura del injerto.

radrapo de $5 \mathrm{~cm}$ de ancho. Los vendajes fueron cambiados cada $24 \mathrm{~h}$ durante la primer semana. A medida que se produjo la cicatrización y disminuyó el drenaje de la herida, el vendaje se cambió con menos frecuencia, cada 48 h y luego cada 72 h. Evaluaciones macroscópicas fueron realizadas durante todo este tiempo teniendo en cuenta la vitalidad del tejido y la formación de tejido de granulación entre los orificios de la malla.

Los puntos fueron retirados el día 14 después del procedimiento quirúrgico y ese día se realizó la primer biopsia, para conocer las probables modificaciones que ocurrieron en la estructura del tejido. La biopsia final fue tomada a cada paciente en un día determinado, de acuerdo al tiempo completo de cicatrización, que varió entre cada uno de ellos. Hisopados de las heridas quirúrgicas fueron tomadas cada $48 \mathrm{~h}$ la primer semana, a manera de conocer la flora bacteriana presente en el proceso de cicatrización.

En todos los pacientes, el control post operatorio fue realizado cada $24 \mathrm{~h}$ los primeros 6 días, luego se realizaron cada $48 \mathrm{~h}$ hasta el día 25 , y luego cada $72 \mathrm{~h}$ a partir del día 33 del control. El vendaje fue retirado de cada paciente una vez que se consideró óptimo, es decir, cuando la superficie del injerto iniciaba el proceso de epitelización. Al finalizar el trabajo y la evaluación de los animales, éstos fueron destinados a propietarios que los aceptaron en adopción.

Los parámetros clínico quirúrgicos utilizados para evaluar la cicatrización incluyeron cambios de coloración, formación de tejido de granulación de color rojo brillante que rellene las cavidades de la malla a medida que progresara la cicatrización y desaparición de la línea de incisión inicial. Los cálculos estadísticos se efectuaron aplicando el test " $t$ " de Student, comparando el proceso de cicatrización tisular en función del tiempo, con un nivel de confianza del 95\%, utilizando el paquete estadístico Epi Info 3.1, con un nivel de significancia del $5 \%(\mathrm{p}<0,05) 1,9,10,14$.

Los resultados fueron interpretados según el criterio clínico de evaluación del patrón de cicatrización de acuerdo a la bibliografía de referencia, y por medio de los estudios de biopsia tisular. Estimaciones macroscópicas fueron realizadas cada $24 \mathrm{~h}$ durante la primer

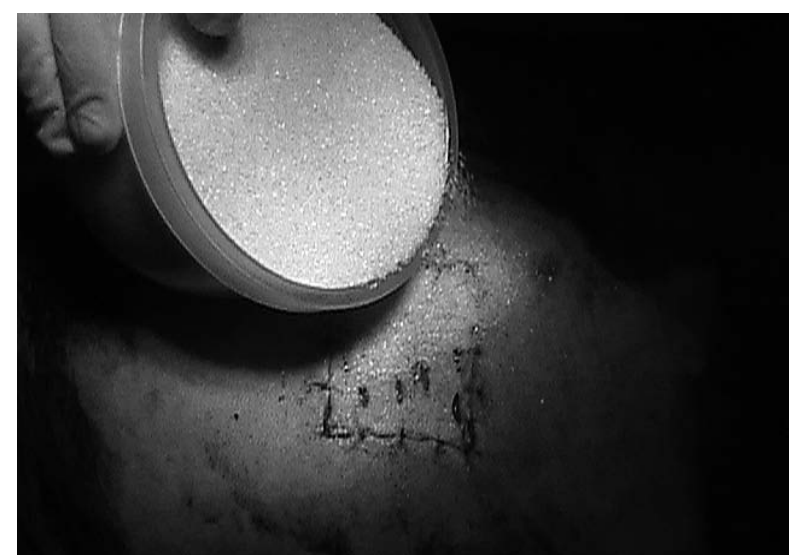

Figura 5. Colocación de azúcar granulado sobre el injerto.

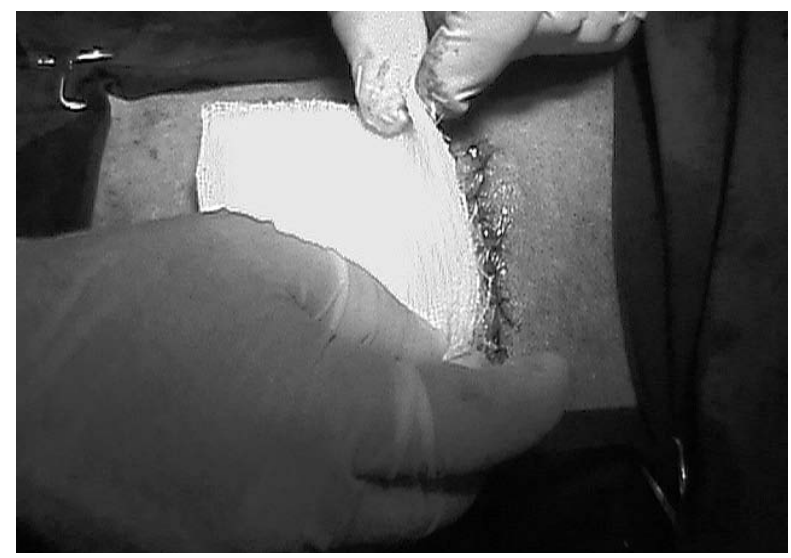

Figura 6. Aplicación del apósito con nitrofurazona al $0,2 \%$

semana, luego cada 48 y 72 h, evaluando principalmente coloración y humedad. Durante todo este tiempo, la valoración estuvo dada por la vitalidad del tejido y la formación de tejido de granulación entre los orificios de la malla. La palidez y/o la cianosis de los injertos fueron consideradas normales hasta las $48 \mathrm{~h}$ debido a la inosculación. La necrosis isquémica seca se presentó en algunos pacientes como una coloración negruzca. Entre las 72 y 96 h se esperó la aparición de una coloración rojo brillante. Hacia los días 7 u 8 posteriores a la cirugía, se consideró que todo el injerto debía estar rojo si la sobrevida hubiera sido completa. Hacia el día 14 la coloración debió ser la normal del animal.

\section{RESULTADOS Y DISCUSIÓN}

En la Tabla 1 se muestra la evolución de la cicatrización tisular, el lapso de relleno de cavidades de la malla del injerto y el tiempo de aparición del proceso de epitelización. La cicatrización se consideró completa una vez que el tejido del injerto hubiera presentado un $100 \%$ de epitelización.

Los pacientes tratados con azúcar granulado completaron el proceso cicatrizal en menor tiempo que los tratados con nitrofurazona, en los cuales finalizó de 7 a 17 días después. Tales diferencias carecieron de significación estadística, circunstancia que podría atribuirse 
Tabla 1. Tiempos de cicatrización, relleno de malla y epitelización del injerto.

\begin{tabular}{lccc}
\hline tratamiento & $\begin{array}{c}\text { cicatrización } \\
\text { (días) }\end{array}$ & $\begin{array}{c}\text { relleno } \\
\text { (días) }\end{array}$ & $\begin{array}{c}\text { epitelización } \\
\text { (días) }\end{array}$ \\
\hline nitrofurazona $0,2 \%$ & $54 \pm 0$ & $20,5 \mathrm{a} \pm 6,36$ & $31,5 \mathrm{a} \pm 2,12$ \\
azúcar granulado & $42 \pm 7,07$ & $6,0 \mathrm{~b} \pm 0$ & $23,0 \mathrm{~b} \pm 0$ \\
\hline
\end{tabular}

Cicatrización: tiempo total (promedio) de cicatrización; Relleno: tiempo de relleno total de la cavidad de la malla; Epitelización: tiempo de epitelización total. Valores en media aritmética \pm desvío estándar; a,b: indican diferencias estadísticamente significativas $(\mathrm{p}<0,05)$.

a la escasa cantidad de unidades muestrales utilizadas. No obstante, las diferencias matemáticas indicarían un mayor poder cicatrizantes del azúcar, el cual genera migración de agua y linfa fuera del tejido, hacia la solución de azúcar, inhibiendo el crecimiento bacteriano por disminución en la "Aw" del sustrato ${ }^{15}$. La linfa a su vez provee nutrientes al tejido ${ }^{12}$. En la Tabla 1 también puede observarse que el tiempo transcurrido hasta el relleno total de la cavidad de la malla del injerto y el lapso de epitelización (considerado como referencia para el retiro del vendaje), fueron estadísticamente menores $(p<0,05)$ en los pacientes tratados con azúcar.

La evaluación histopatológica de los animales tratados con azúcar reveló un adecuado proceso de cicatrización, caracterizada por un estrato epidérmico uniforme y disposición paralela de las fibras colágenas, con estrato epitelial hiperplásico de 13 a 15 capas de células revestidas con estrato córneo laminar, dermis superficial con densas fibras colágenas e hiperplasia de los folículos pilosos. En cambio, en los pacientes tratados con nitrofurazona el patrón no fue uniforme. Uno de los perros presentó folículos pilosos que no evidenciaban células epiteliales y un infiltrado de células inflamatorias mononucleares, neutrófilos y eosinófilos, en coincidencia con las evaluaciones clínicas, que demostraron ausencia de pelos en zonas del injerto. El otro perro tratado con nitrofurazona reveló hiperplasia de folículos pilosos y de glándulas sudoríparas y sebáceas, reacción focal mononuclear y polimorfonuclear neutrofílica y eosinofílica.

En estudios similares utilizando azúcar granulado como capa de contacto en un paciente sometido a autoinjerto (piel de escroto) en malla de espesor completo, se logró una adecuada cicatrización en un período de 9 días, lapso al término del cual ya no existía tejido necrótico ni exudado, momento en que se reemplazó el vendaje con azúcar por una capa de contacto de alginato de calcio y el tiempo de recambio de vendaje se realizó cada 48 horas ${ }^{8}$.
En conclusión, los resultados obtenidos demuestran la eficacia del azúcar granulado en el injerto cutáneo en malla de espesor completo del perro, con el cual se logra acortar el proceso de cicatrización, en comparación con el lapso obtenido con el uso de nitrofurazona, además de mejorar estadísticamente el tiempo de relleno de la malla y el período de epitelización.

\section{REFERENCIAS}

1. Argimón J, Jiménez J. 2009. Métodos de investigación clínica y epidemiológica, $3^{\mathrm{a}}$ ed., Elsevier, Barcelona, $393 \mathrm{p}$.

2. Cim M. 2002. Evidencia científica sobre uso del azúcar en heridas [Internet, acceso 15-6-2008]. Disponible en: http//es.geocities.com/carlosGerena/2/higiazucar

3. Fossum T, Hedlund C, Hulse D, Johnson A. 1997. Cirugía en pequeños animales, $2^{\mathrm{a}}$ ed., Intermédica, Buenos Aires, 1282 p.

4. García C, Pérez F. 1976. Patología quirúrgica de los animales domésticos, $7^{\mathrm{a}}$ ed., Científico-Médica, Barcelona.

5. González J, Ávila I, San Román F. 1994. Cirugía veterinaria, McGraw-Hill Interamericana, Barcelona, 884 p.

6. González J. 2004. Heridas, métodos de tratamiento [monografía en Internet, acceso 15-6-2008]. Disponible en: http//www.aamefe.arg/curacion_azucar.htm

7. Hellebrekers LJ. 2006. Manejo del dolor en medicina veterinaria, $1^{\circ}$ ed., Intermédica, Buenos Aires.

8. Henke J, Erhardt W. 2008. Control del dolor en pequeños animales y mascotas. $1^{\mathrm{a}}$ ed., Masson, Barcelona.

9. Hernández R, Fernández C, Baptista P. 2003. Metodología de la investigación cientifica, $3^{\mathrm{a}}$ ed., McGraw Hill, Mexico.

10. Hulley S, Cummings S, Browner W, Grady D, Newman T. 2007. Diseño en investigaciones clínicas, $3^{\text {a }}$ ed., Kluwer, Mexico.

11. Merchán E. 2008. Manejo y tratamiento de heridas. [monografía en Internet, acceso: 15-6-2008]. Disponible en $\mathrm{http} / /$ wwwscielo.isciii.es/cielo

12. Slatter J, Douglas H. 2006. Tratado de cirugía en pequeños animales, $3^{\mathrm{a}}$ ed., Intermédica, Barcelona.

13. Sumano H, Ocampo L. 1997. Farmacología veterinaria, $2^{a}$ ed., McGraw-Hill Interamericana, México.

14. Triola M. 1999. Estadística, $9^{\mathrm{a}}$ ed., Pearson, Nueva York, 1999.

15. Welti J. 1998. Investigación en ciencia y tecnología de alimentos. Cuad Nutr (México) 21: 21-28.

16. Zamora-Castro S, Flamana MJ, Rivero Y. 2006. Experiencia en la cura de úlceras por presión con sacarosa. Rev Cubana Enfermer. On line: http://scielo.sld.cu/sci elo. php?pid=S0864-03192006000300006\&script $=$ sci_abstract 